\title{
Food fight: Perhaps there is a benefit to being fat and happy
}

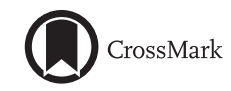

\author{
Megan Horsley, RD, CSP, CNSC, LD, Amiee Trauth, MS, RD, CNSC, LD, and David S. Cooper, MD, MPH
}

From The Heart Institute, Cincinnati Children's Hospital Medical Center, Cincinnati, Ohio.

Disclosures: Authors have nothing to disclose with regard to commercial support.

Received for publication Jan 29, 2018; accepted for publication Jan 31, 2018; available ahead of print Mar 9, 2018.

Address for reprints: David S. Cooper, MD, MPH, The Heart Institute, Cincinnati Children's Hospital Medical

Center, 3333 Burnett Ave, MLC 2003, Cincinnati, OH 45229 (E-mail: David.Cooper@ cchmc.org).

J Thorac Cardiovasc Surg 2018;155:2110-1

$0022-5223 / \$ 36.00$

Copyright (c) 2018 by The American Association for Thoracic Surgery

https://doi.org/10.1016/j.jtcvs.2018.01.064

Adequate caloric intake plays a vital role in the course (and recovery) of critically ill patients. Nutritional status and nutrient delivery during critical illness has been linked to mortality and other clinical outcomes, such as poor growth, increased incidence of infection, poor wound healing, prolonged ventilation, increased length of stay, and poor neurodevelopmental outcomes. ${ }^{1-3}$ In addition, early enteral nutrition has been demonstrated to decrease morbidity and length of stay in critically ill populations. ${ }^{4}$ In this issue of the Journal, Piggott and colleagues ${ }^{5}$ describe how inadequate preoperative calorie intake is associated with higher inotropic scores, higher lactate levels, and increased ventilator-days, and is also independently associated with the development of postoperative acute kidney injury. However, an association with mortality remains an elusive demonstrable outcome.

Although achieving optimal nutrition in the preoperative neonate is desirable, there are many challenges to achieving adequate nutritional intake, such as fluid restriction, heart failure (pulmonary overcirculation), limited gastrointestinal perfusion and concern for necrotizing enterocolitis (NEC), oral feeding difficulties, and increased energy expenditure.

Preoperative fluid restriction is not as prevalent as postoperatively restriction; however, oral feeds are commonly limited or prohibited in patients with ductal-dependent circulation. Alten and colleagues ${ }^{6}$ demonstrated a large variation among preoperative feeding practices and approaches to feedings among cardiac centers in the Pediatric Cardiac Critical Care Consortium $\left(\mathrm{PC}^{4}\right)$. They found that preoperative feeding rates ranged from $29 \%$ to $79 \%$ across $\mathrm{PC}^{4}$ centers, with only slightly more than one-half of the neonates receiving preoperative feeds. Despite this variation in practice, many centers have begun to develop or already have in place preoperative feeding guidelines and algorithms to standardize practice and ensure patient safety. ${ }^{7}$ A survey from the National Pediatric Cardiology Quality Improvement Collaborative (NPC-QIC) reported that 30 of 46 centers feed single-ventricle neonates preoperatively. ${ }^{8}$ Nonetheless, at present there is minimal prospective,

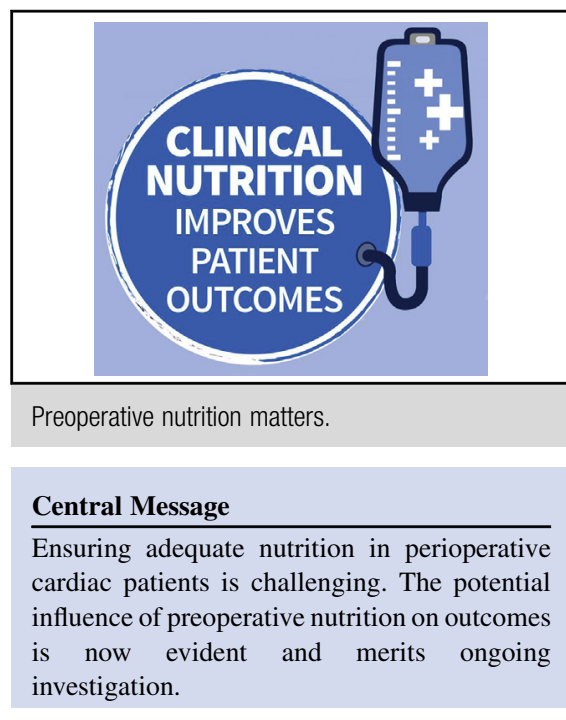

See Article page 2104.

controlled evidence to support the safety and/or benefit of preoperative enteral nutrition in neonatal cardiac surgery recipients. Recent publications suggest that preoperative feeds may be safe and may improve postoperative feeding tolerance and other clinical outcomes in this high-risk population. ${ }^{9,10}$ Toms and colleagues ${ }^{10}$ found that neonates with hypoplastic left heart syndrome who received preoperative trophic feeds had a shorter duration of postoperative mechanical ventilation, less fluid overload, and earlier postoperative feeding tolerance compared with those who did not receive such feeds. This may suggest that early enteral nutrition may help to mitigate one's response to stress.

In this study by Piggott and colleagues, ${ }^{5} 30.5 \%$ of patients achieved their preoperative calorie goal, and approximately $70 \%$ reached their protein goal. Nonetheless, there is a limited description of the approach for these patients, and we are left wondering how these patients were fed in terms of volume per kilogram per day, calorie concentration, and type of feeding. This information is relevant, because implementation of breast milk has been linked to the prevention of NEC, which potentially could improve tolerance and enteral feeding in this population. According to the 2012 American Society for Parenteral and Enteral Nutrition (ASPEN) clinical guidelines for nutritional support of neonatal patients at risk for NEC, ${ }^{11}$ patients who may be at high risk for NEC should be started on enteral nutrition within the first 2 days of life, and human milk is the preferred choice for these neonates. Total parenteral nutrition (TPN) is often used in this patient population, 
given the aforementioned hemodynamic concerns to promote optimal intake. Piggott and colleagues ${ }^{5}$ discuss the challenges in using TPN, which include cost factors and the morbidities associated with prolonged use, but recent national shortages will further limit the use of TPN to provide adequate nutrition. In addition, there are only limited data indicating that early TPN (before 1 week of illness) in critically ill children is associated with worse outcomes. $^{12}$

Pediatric malnutrition was recently redefined by ASPEN as "an imbalance between nutrient requirement and intake, resulting in cumulative deficits of energy, protein, or micronutrients that may negatively affect growth, development, and other relevant outcomes". ${ }^{13}$ This definition is only meant to be used for children age $>1$ month, making the diagnosis of malnutrition in neonatal cardiac surgery recipients challenging. Piggott and colleagues ${ }^{5}$ report on using World Health Organization $z$-scores and preoperative triceps skin fold measurements as a means to measure nutritional status. Although triceps skin folds are an adequate preoperative measure of fat stores, this technique is not applicable to neonates. Subjective global assessment and weight, length, and head circumference $z$-scores along with a nutrition-focused physical examination remains the preferred approach to assessing neonatal nutrition. Individualized nutritional prescriptions via indirect calorimetry is the gold standard but is underused in this patient population. ${ }^{14,15}$ Piggott and colleagues ${ }^{5}$ used predictive equations to determine calorie goals, but given the heterogeneity of critically ill patients, predictive equations can often lead to overfeeding or underfeeding. They present general calorie goals for extubated patients and those receiving TPN, but their results would have been strengthened by the use of indirect calorimetry and the inclusion of actual intakes of both groups of patients both preoperatively and postoperatively.

More research on the importance of how preoperative nutrition affects postoperative outcomes is warranted. Piggott and colleagues ${ }^{5}$ have nicely started this work by describing how inadequate preoperative nutrition impacts postoperative outcomes. In particular, prospective studies that appropriately control for age, weight, timing of surgery, and mode of nutritional support will further delineate the influence of preoperative nutrition.

\section{References}

1. Bechard LJ, Duggan C, Touger-Decker R, Parrott JS, Rothpletz-Puglia P, Byham-Gray L, et al. Nutritional status based on body mass index is associated with morbidity and mortality in mechanically ventilated critically ill children in the PICU. Crit Care Med. 2016;44:1530-7.

2. Mehta NM, Bechard LJ, Cahill N, Wang M, Day A, Duggan CP, et al. Nutritional practices and their relationship to clinical outcomes in critically ill children: an international multicenter cohort study. Crit Care Med. 2012;40:2204-11.

3. Mitting R, Marino L, Macrae D, Shastri N, Meyer R, Pathan N. Nutritional status and clinical outcome in postterm neonates undergoing surgery for congenital heart disease. Pediatr Crit Care Med. 2015;16:448-52.

4. Velazco CS, Zurakowski D, Fullerton BS, Bechard LJ, Jaksic T, Mehta NM. Nutrient delivery in mechanically ventilated surgical patients in the pediatric critical care unit. J Pediatr Surg. 2017;52:145-8.

5. Piggott KD, Liu A, Monczka J, Fakioglu H, Narasimhulu SS, Pourmoghadam K, et al. Inadequate preoperative nutrition might be associated with acute kidney injury and greater illness severity postoperatively. J Thorac Cardiovasc Surg. 2018:155:2104-9.

6. Alten JA, Rhodes LA, Tabbutt S, Cooper DS, Graham EM, Ghanayem N, et al. Perioperative feeding management of neonates with CHD: analysis of the Pediatric Cardiac Critical Care Consortium (PC4) registry. Cardiol Young. 2015;25: 1593-601.

7. Manuri L, Morelli S, Agati S, Saitta MB, Oreto L, Mandraffino G, et al. Early hybrid approach and enteral feeding algorithm could reduce the incidence of necrotising enterocolitis in neonates with ductus-dependent systemic circulation. Cardiol Young. 2017;27:154-60.

8. Slicker J, Sables-Baus S, Lambert LM, Peterson LE, Woodard FK, Ocampo EC, et al. Perioperative feeding approaches in single ventricle infants: a survey of 46 centers. Congenit Heart Dis. 2016;11:707-15.

9. Zyblewski SC, Nietert PJ, Graham EM, Taylor SN, Atz AM, Wagner CL. Randomized clinical trial of preoperative feeding to evaluate intestinal barrier function in neonates requiring cardiac surgery. J Pediatr. 2015;167:47-51.

10. Toms R, Jackson KW, Dabal RJ, Reebals CH, Alten JA. Preoperative trophic feeds in neonates with hypoplastic left heart syndrome. Congenit Heart Dis. 2015; 10:36-42.

11. Fallon EM, Nehra D, Potemkin AK, Gura KM, Simpser E, Compher C, et al. ASPEN clinical guidelines: nutrition support of neonatal patients at risk for necrotizing enterocolitis. JPEN J Parenter Enteral Nutr. 2012;36:506-23.

12. Fivez T, Kerklaan D, Mesotten D, Verbruggen S, Wouters PJ, Vanhorebeek I, et al. Early versus late parenteral nutrition in critically ill children. $N$ Engl $J$ Med. 2016;374:1111-22.

13. Mehta NM, Corkins MR, Lyman B, Malone A, Goday PS, Carney LN, et al Defining pediatric malnutrition: a paradigm shift toward etiology-related definitions. JPEN J Parenter Enteral Nutr. 2013;37:460-81.

14. Mehta NM, Skillman HE, Irving SY, Coss-Bu JA, Vermilyea S, Farrington EA, et al. Guidelines for the provision and assessment of nutrition support therapy in the pediatric critically ill patient: Society of Critical Care Medicine and American Society for Parenteral and Enteral Nutrition. JPEN J Parenter Enteral Nutr. 2017;41:706-42.

15. Mehta NM, Bechard LJ, Leavitt K, Duggan C. Cumulative energy imbalance in the pediatric intensive care unit: role of targeted indirect calorimetry. JPEN J Parenter Enteral Nutr. 2009;33:336-44. 